\title{
Identifying Different Risk Factors of Cervical Cancer in Rural Women Population of Lucknow West, India: A 5 Years Study
}

\author{
${ }^{1}$ Professor of Pathology, India \\ ${ }^{2}$ Department of Pathology, India \\ ${ }^{3}$ Department of Obstetrics and Gynaecology, India \\ ${ }^{4}$ Department of Pathology, India \\ ${ }^{5}$ Chancellor, Era University, India
}

Srivastava Anand Narain ${ }^{1}$, Misra Jata Shankar ${ }^{2 *}$, Kunwar Shipra ${ }^{3}$, Fatima Naseem ${ }^{4}$ and Khan Mohshin Ali ${ }^{5}$

Received: 阱 August 30, 2018; Published: 盋 September 07, 2018

*Corresponding author: Misra Jata Shankar, Department of Pathology, India

\section{Short Communication}

Carcinoma cervix is a major health problem faced by Indian women and though its incidence has declined in urban population in recent years but in the rural India where $70 \%$ of the people dwell, cervical cancer still remains on top [1]. It is mainly due to illiteracy and ignorance about the factors contributing to the development of cervical cancer. The rural women are mostly poor and backward, have poor genital hygiene and are not aware of major risk factors like marriage at an early age and multiparity [2]. Therefore, creating awareness about the hazards of cervical cancer and apprising them regarding the importance of early detection of the disease and associated risk factors are the need of the hour [3,4]. Cervical cancer screening program is currently going on in the villages of Lucknow, West through camp approach under the auspices of Era's Lucknow Medical College and Hospital, Lucknow, India since May, 2013. Till July 2018, 154 camps have been organized through counseling and motivation of women in 129 villages. In each village, 100 women were counseled and a total of 4685 women have attended the camps from 15400 women motivated (30.4\%). Pap smear was collected in 2603 of these women (55.5\%). Pap smears were stained according the Papanicalou's technique and cytopathological changes observed in the cervical smears have been graded according to the Bethesda system of classification of 1993 [5]. The cervical smears of the total 2603 women examined revealed following cytopathological changes in the cervix: Total numbers of

i. Squamous intraepithelial lesions of cervix (SIL) -473(18.1\%)

a) Low squamous intraepithelial lesions (LSIL) - $-449(17.2 \%)$ b) High squamous intraepithelial lesions (HSIL) - $-24(0.9 \%)$

ii. Carcinoma cervix

The SIL incidence was very high in rural women than $7.2 \%$ noticed in urban population of Lucknow though majority of them were of low grade (LSIL) [6,7]. Necessity is, therefore, felt to identify risk factors associated with SIL development. For this, the SIL incidence has been extensively analyzed in relation to age, parity, gynaecological symptoms and literacy status etc. The SIL incidence in relation to symptomatic status revealed no significant difference from the asymptomatic women $(18.8 \%$ as against $16.6 \%$ ). The reluctance of the rural women in telling their gynaecological problems might be the reason for a low SIL incidence in symptomatic women. However, a high SIL rate has been reported by many investigators in symptomatic women than asymptomatic cases $[8,9]$. The SIL incidence in relation to age showed no significant difference in women up to 40 years of age than in older women above 40 years of age (18.3\% as against $17.1 \%)$. It should be pointed out here that majority of women attending the camp were young and sexually active and most of them were literate while the older women were mostly illiterate and their camp attendance was poor. This has also been reported by Nikumbh et al. [10]. Hence, relationship between old age and development of cervical cancer could not be ascertained. The analysis of SIL incidence in relation to parity showed significant difference between low and mutiparity (19.5\%) as against $17.1 \%)$. It appears that mutiparity is a significant risk factor for the development of cervical cancer in these women. This has also been stressed in their findings by Rajput 
et al., Dasgupta et al. and Raichoudhary et al. [11-13]. As regards gynaecological symptoms, vaginal discharge and vague pain in lower abdomen were the commonest symptom encountered in the rural women and SIL rate with these symptoms was also higher than the menstrual disorders $(21.4 \%$ and $17.2 \%$ respectively as against $12.5 \%$ ). This has also been reported by Srivastava et al. [14], Nikumbh et al and Rajput et al. The other gynaecological disorders like contact bleeding and postmenopausal bleeding were rarely encountered but the SIL rate was very high in these women.

The literacy status in 2603 women in whom cervical cytology has been done revealed almost no difference in the SIL incidence in the illiterate and literate women. It appears that proper counseling and motivation plays more important role than literacy in camp attendance and opting for the Pap smear examination. Education as the fundamental factor increasing awareness of the disease in rural women has been stressed by Nene et al. [15] and Thulaseedharan et al. [16]. However, poor genital hygiene is the major cause of different sexually transmitted diseases like Candida albicans, Trichomonas vaginalis, HPV and HSV occurring in these women [17]. From the present observations, need is felt to create awareness about the different risk factors delineated above among the rural women. Among these prominently are multiparity and women complaining of vaginal discharge and pain in lower abdomen. This can be easily assessed while counseling and motivating these women for attending the camp. The gravity of the disease and different associated hazards are to be explained to them with special reference to the immense importance of early detection of disease by Pap smear and whenever needed, HPV-DNA estimation must be done. They have to be told that if the cancer is diagnosed at early age, it can be easily cured. The Government of India through National Cancer Control Program may play a major role in this direction and can minimize the agony of rural women by checking the incidence of carcinoma cervix by adapting different measures suggested above. The coming decade, it is hoped, will bring significant improvement in the lifestyle of rural women and their literacy status as well.

\section{Acknowledgement}

The authors are grateful to Era's Lucknow Medical College Management and Secretary, Era's Educational trust for all the financial grant and infrastructural facilities for this camp based Rural study in Lucknow West.

\section{References}

1. (2009) National Cancer Registry Program (NRCP-ICMR) Time trends and cancer incidence rates: 1982-2005. Bangalore: NRC
2. Badwe DA, Dixit R, Laversanne M, Bray F (2014) Cancer incidence trends in India. Jpn J Clin Oncol 44(5): 401-407.

3. Dhamija S, Sehgal A, Luthra UK, Sehgal K (1993) Factors associated with awareness and knowledge of cervical cancer in a community: Implication for health education program in developing countries. JR Soc Health 113(4): 184-186.

4. Tripathi N, Kadam YR, Dhobale RV, Gore AV (2014) Barriers for early detection of cancer among Indian rural women. South Asian J Cancer 3(2): 122-127.

5. (1993) Bethesda system of reporting vaginal: cervical cytological diagnosis. Acta Cytol 57(2): 115-20.

6. Misra JS, Srivastava AN, Gupta HP (2017) Impact of literacy status on the cervical cancer screening in rural women of India. Invest Gynaecol Res Women Health 1(2).

7. Misra JS, Srivastava AN, Singh U (2009) Risk factors and strategies for control of carcinoma cervix in India: Hospital based cytological screening of 35 years. Ind J Cancer 46(2): 155-159.

8. Ambedkar RKV, Srinivasmurthi BC, Balamrurugan M (2015) Clinicopatological significance of Pappinocalaou smears study of postmenopausal women in a rural tertiary care centre. Clin Cancer Investig 4(2): 147-151.

9. Bukhari H, Saba K (2012) Clinicopathological importance of Pap smears for diagnosis of premalignant and malignant lesions of cervix J Cytol 29(1): $20-25$

10. Nikumbh DB, Nikumbh RD, Dombale VD, Jagtap SV, Desai SR (2012) Cervicovaginal cytology: Clinicopathological and social aspect of cervical cancer screening in Rural Maharashtra, India. Int J Health Sci Res 2: 125132.

11. Raychaudhari S, Mandal S (2012) Sociodemographic and behavioural risk factors for cervical cancer and knowledge, attitude and practice in rural and urban areas of North Bengal, India. Asian Pac J Cancer Prev 13(4): 1092-1096.

12. Rajput N, Verma YS, Ahirwar G (2013) Detection of abnormal cervical cytology by Pap smear and comparison between rural and urban women. Journal Evol Med Dental Sci 2(41): 7923-7930.

13. Das Gupta A, Naskar NN, Ram R, Deb S (2012) A community based study of the prevalence of risk factor of carcinoma cervix in married women of rural area of West Bengal. Ind J Community Med 27(3): 36-39.

14. Srivastava M, Srivastava OP, Jaiswal SS (2011) Pattern of cervical smear cytology in Rural medical college. Pravera Med Rev 31: 4-8.

15. Nene BM, Jayanth K, Malvi SG, Dale PS, Deshpande R (1994) Experience in screening for cervical cancer in rural areas of Barshi Tehsil (Maharashtra). Ind J Cancer 31(1): 34-40.

16. Thulaseedharan JV, Malila N, Hakama M, Swaminathan R, Esmy PO, et al. (2012) Effect of screening on the risk estimates of socio-demographic factors on cervical cancer- a large cohort study from Rural India. Asian Pac J Cancer Prev 13(6): 2991-2995.

17. Arora BB, Maheshwari M Devgan N, Arora DR (2014) Prevalence of trichomoniasis, vaginal candidiasis, Genital herpes, chlamydiasis and Actinomycosis among urban and rural women of Haryana, India. J Sex Transm Dis. 
(C) (P) This work is licensed under Creative

To Submit Your Article Click Here: $\quad$ Submit Article

DOI: $10.32474 /$ OAJOM.2018.02.000143

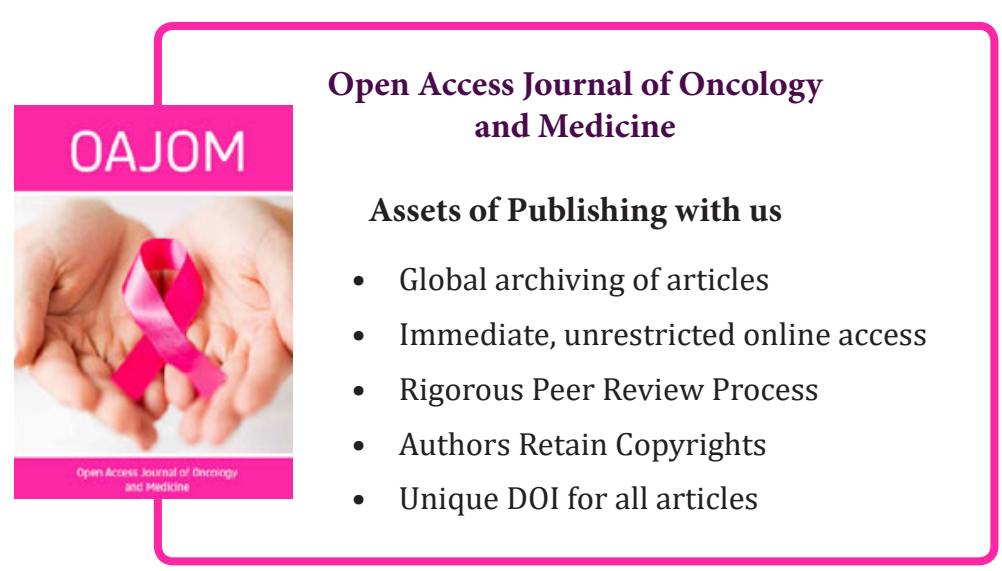

